ECCOMAS

Proceedia
COMPDYN 2021

$8^{\text {th }}$ ECCOMAS Thematic Conference on Computational Methods in Structural Dynamics and Earthquake Engineering

M. Papadrakakis, M. Fragiadakis (eds.)

\title{
FRAGILITY ASSESSMENT OF WIND-EXCITED VIDEO SCREEN ROOMS IN HIGH-RISE BUILDINGS
}

\author{
Fabio Rizzo ${ }^{{ }^{*} \text {, }}$ Laura Ierimonti ${ }^{2}$, Stefano Sacconi ${ }^{2}$, Ilaria Venanzi ${ }^{2}$ \\ 'Gabriele D’Annunzio University, Pescara, Italy, fabio.rizzo@unich.it \\ ${ }^{2}$ University of Perugia, Perugia, Italy, laura.ierimonti@unipg.it, stefa- \\ no.sacconi@collaboratori.unipg.it, ilaria.venanzi@unipg.it
}

\begin{abstract}
High-rise buildings with unusual shapes and high-technological systems are commonly used by companies to represent their economic power. In many cases, equipment consisting of LED screen walls is frequently not compatible with wind-induced displacements and accelerations experienced at high floors. The aim of the research work is to design and optimize a control device for response reduction of a prismatic room equipped with LED screen walls on all sides. The control system is a passive sliding device located at the base of the room disconnecting the LED supporting frame from the building's floor. Fragility analysis is carried out to compute the probability of exceeding predetermined displacements and acceleration thresholds with and without the control system.
\end{abstract}

Keywords: Video walls, high-rise building, wind-induced vibration, wind tunnel tests, base isolation.

\section{INTRODUCTION}

The wind induced vibration is an important topic for high-rise building with unusual shape because torsional effects and large oscillation along and across wind may affect the occupants' comfort largely discussed in literature [1-7]. A few information and recommendations are given by codes and literature for non-structural elements inside buildings that can be severely damaged and therefore can influence costs of construction and maintenance. This is the case of LED screen walls which are used to disseminate entertainment messages and information. They are sensitive to the floor wind induced vibration that can give significant deformation to the wall and a consequent malfunctioning or collapse. 
The LED screen walls operation is frequently not compatible with wind-induced displacements and accelerations experienced at high floors in high-rise buildings. The proper functioning of these high-technological devices can therefore require the installation of local control systems to reduce wind induced vibrations.

In this paper, the wind-induced response of a LED video screen room was reduced by means of passive control system consisting in a base isolated floor which disconnects the substructure from the building. The probability of exceeding predetermined displacements and acceleration thresholds with and without the control system was investigated through fragility analysis based on the PEER integral equation [8-10]. This allows to consider all the possible sources un uncertainties involved in the problem, like those related to wind load characterization, structural modeling and analysis and damage occurrence [11-14]. Calculation was computed on the high-rise building illustrated in Fig.1 and discussed in Section 3. Metti un riferimento ad un tuo articolo precedente

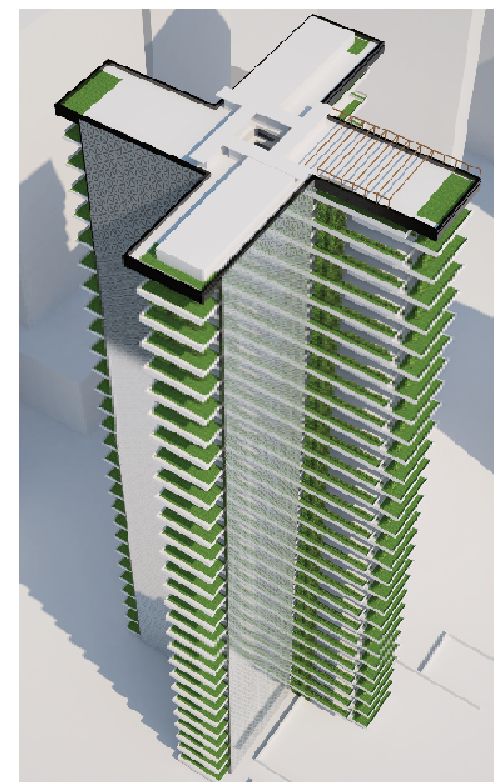

Fig. 1 Numerical model of the pultruded GRP-Tubes substructure Metti un riferimento all'articolo da dove hai preso la figura (se già pubblicata)

\section{PROBABILITY-BASED DESIGN APPROACH}

The proposed methodology for the design of video screen rooms inserted in high-rise buildings accounts for randomness in the load characterization, the structural response estimation and the damage occurrence and exploits the PEER (Pacific Earthquake Engineering Research) equation $[8,9]$. The annual probability of exceeding a selected level of damage is computed as follows:

$$
P_{f}\left(\frac{Z}{H}, D S\right)=\iint P(D S \mid E D P) f\left(E D P \mid I M, \frac{Z}{H}\right) f\left(I M \mid \frac{Z}{H}\right) d E D P d I M
$$

where $D S$ is the selected damage state; $E D P$ is the engineering demand parameter associated to the i-th $D S ; P(D S \mid E D P)$ is the fragility curve, i.e. the complementary cumulative distribution function (CCDF) evaluated for the specific $E D P(D S)$ under investigation; the term $f(I M \mid Z / H)$ represents the probability density function (PDF) of the intensity measure (IM), i.e., the reference mean wind speed evaluated at $Z / \mathrm{H}$; the term $f(E D P \mid I M, Z / H)$ represents 
the probability density function (PDF) of the selected EDP conditional on the value of IM. This probability is evaluated by considering the $\mathrm{N}$ experimental realizations of the structural response components $(E D P)$ evaluated from the FE model.

The $E D P$ are associated to the lateral deformation of a video component (i.e. with and without isolation system); the hammer effect on the corner (i.e. with and without isolation system); acceleration-dependent damages on mechanical components (i.e. with and without isolation system); the achievement of the maximum allowable stroke of the base isolation system.

\section{THE CASE STUDY}

\subsection{The structural setup}

The case study structure is a $300 \mathrm{~m}$ high building with $138 \times 138 \mathrm{~m}$ footprint. The building has 60 floors above ground and interstory height of $5.00 \mathrm{~m}$ [15]. It is assumed that inside the building a technological equipment is inserted consisting in LED screens joined to one another to reproduce screen walls on the lateral surfaces of the room, on the ceiling and on the floor. The screens are supported by a pultruded GRP-Tubes substructure (Fig.2) that is pinned to the building floors. A Finite Element Model of the substructure has been built, using frame and shell elements to perform dynamic analyses.

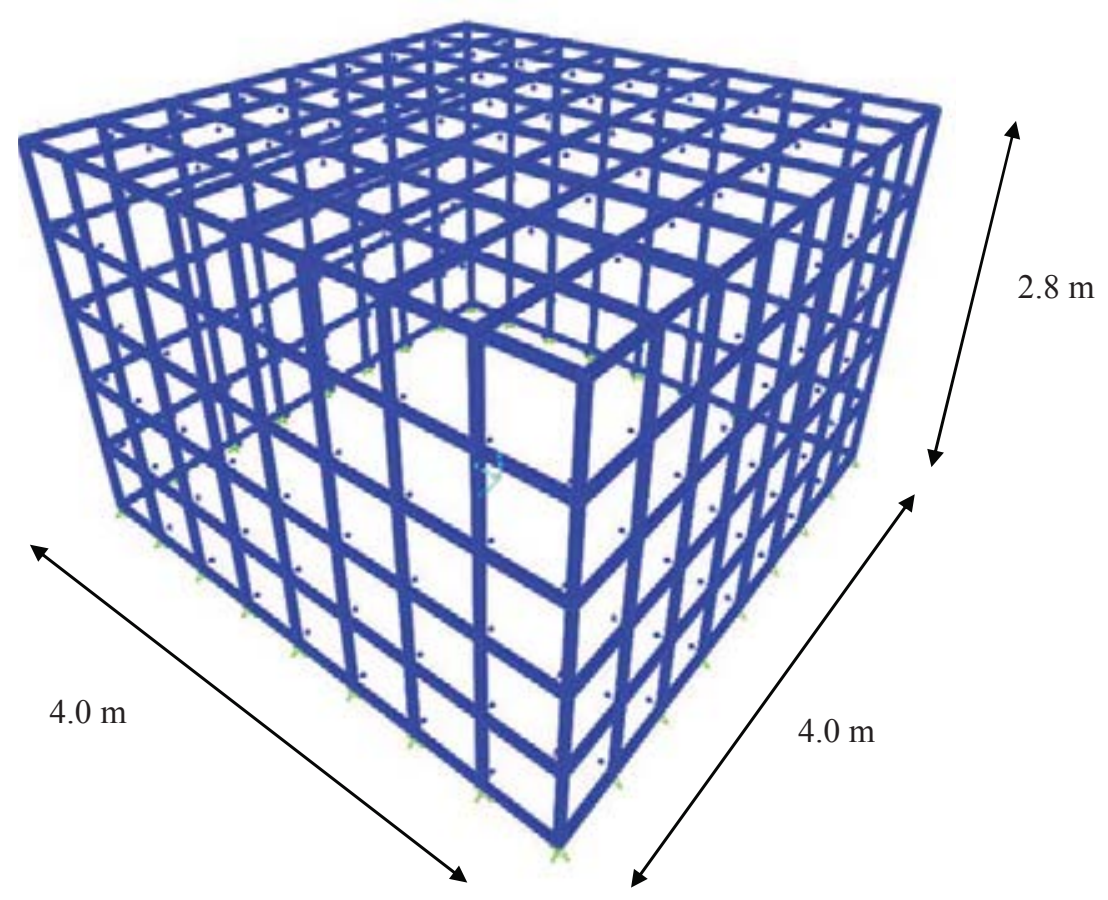

Fig. 2 Numerical model of the pultruded GRP-Tubes substructure

\subsection{Wind tunnel setup}

The floors' accelerations obtained from wind tunnel tests on a 1:400 reduced scale aeroelastic model of the tall building are used to evaluate the response of the substructure. Accelerations were acquired on an aeroelastic model with a sampling frequency equal to $1000 \mathrm{~Hz}$ for a time length equal to $180 \mathrm{~s}$. At the prototype scale it corresponds to a time step equal to $0.05 \mathrm{~s}$ and a time length equal to 9000 s (i.e. 15 intervals 10 minutes long). Figure 3 shows a picture of the 
test model during experiments. The model was equipped with 6 mono-directional accelerometers fixed on 6 floors. The main frequency of the aeroelastic model was equal to $5.86 \mathrm{~Hz}$ and the structural damping ratio was around $2 \%$. The wind velocity profile was assumed equal to the Terrain IV given by [16].

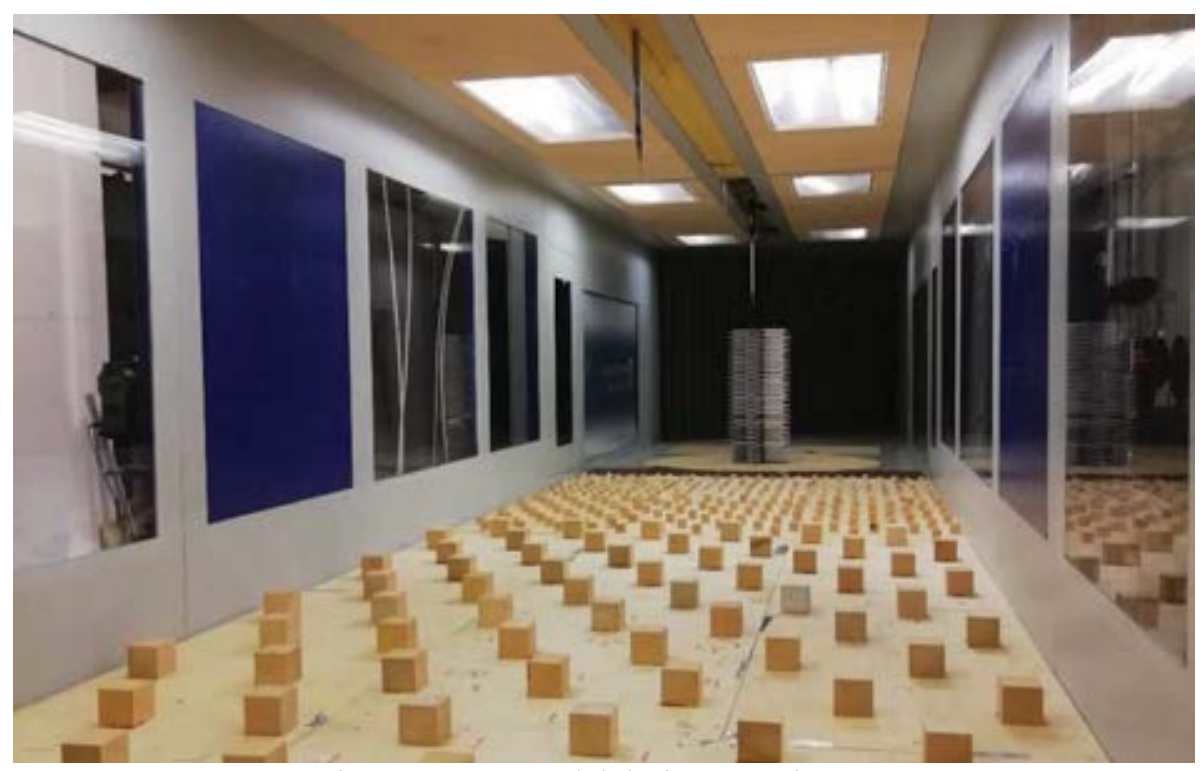

Figure 3: Test model during experiments.

Figure 4 shows the relative peak displacements at the corner of the substructure illustrated in Fig.2. Results illustrated in Fig.4 suggest that after the 30th floor and for a wind speed bigger than $40 \mathrm{~m} / \mathrm{s}$ at the building top, the substructure's displacements and accelerations are not compatible with the proper functioning of the video screens. Indeed, to avoid damage to video wall components, the relative displacements should be contained within a few millimeters. Therefore, it can be suitable equipping the substructure with devices able to reduce the video room response, to avoid damage and ensure proper operating conditions.

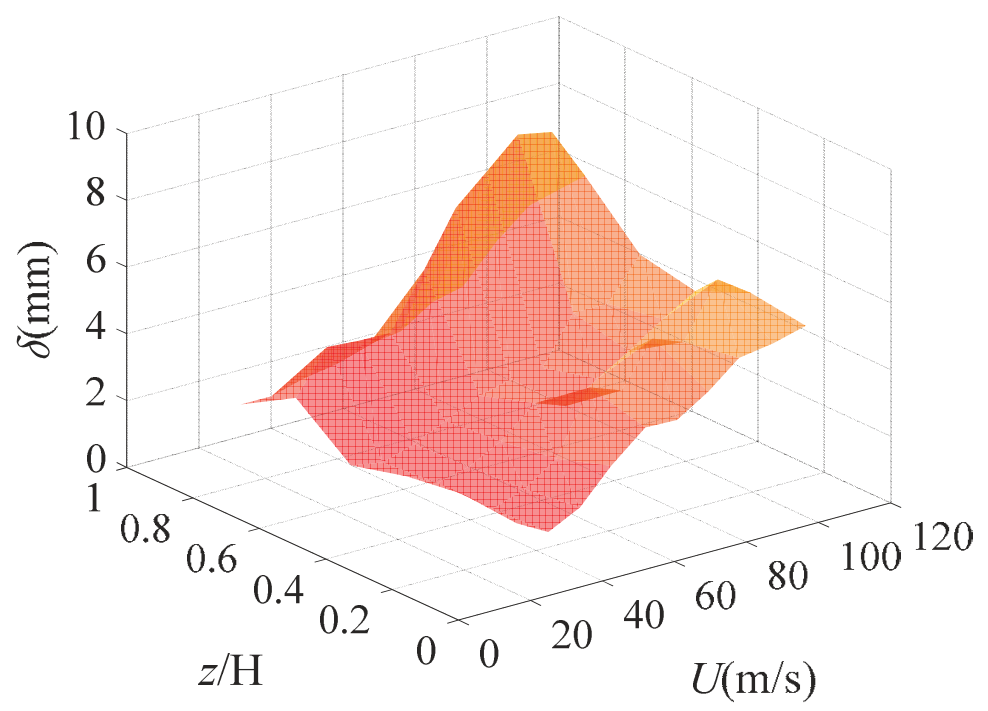

Figure 4: Relative $(\delta)$ peak displacements as a function of wind velocity $(U)$ and height above ground $(z / \mathrm{H})$ at corner of the substructure. 


\subsection{The base isolation system}

To reduce the wind-induced vibration response, a passive control system is designed, consisting in a base isolated floor which disconnects the substructure from the building. The behavior of the base isolation devices has been modeled by a bilinear force-displacement hysteretic model, with $\mathrm{K}_{\mathrm{s}}$ being the stiffness associated to the second branch. The model consists of a spring and a slider and it is similar to devices used for the protection of industrial equipment [17]. The period of the system is defined as $T=2 \pi\left(\mathrm{M} / \mathrm{K}_{\mathrm{s}}\right)^{0.5}$ where $\mathrm{M}$ is the structure's mass and $\mathrm{K}_{\mathrm{s}}$ represents the spring's stiffness.

Figure 5 shows the results of the parametric analysis on the variation of the device's period $T$ and the friction coefficient $\mu$ for the case $\mathrm{z} / \mathrm{H}=1$ and $U=111.8 \mathrm{~m} / \mathrm{s}$, in terms of relative displacements $\delta$ (Fig. 5). The period $T$ varies with the change of Ks, whose interval of investigation ranges from 0.18 to $2793 \mathrm{kN} / \mathrm{m}$. Three different values of the friction coefficients $\mu=0.1$, $\mu=0.3, \mu=0.5$ are considered. From the figure it is possible to observe that the relative displacements $(\delta)$ are closely reduced with respect to those obtained without the isolation system.

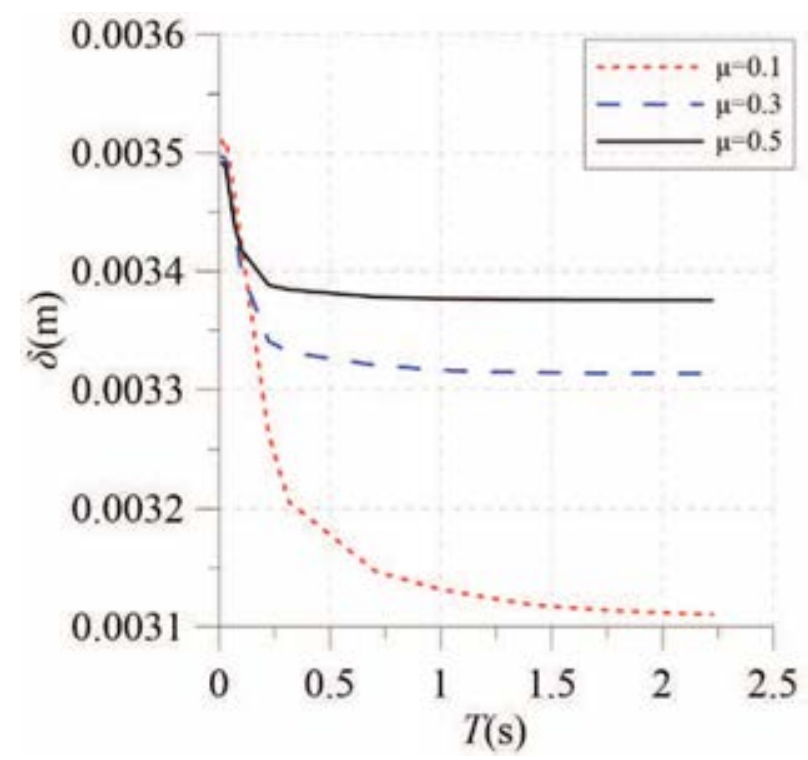

Figure 5: Corner's relative displacements $\delta$ as a function of the period $T$ of the base isolation device.

\subsection{The damage limit states}

The main objective of the present paper is the evaluation of the probability-based performance of a video wall room integrated in a high-rise building by accounting for the occurrence of damages associated to the video components with and without a base isolation system. Hence, four different $D S$ are considered (Table 1): the lateral deformation of a video component; the hammer effect on the corner; acceleration-dependent damages on mechanical components; the achievement of the maximum allowable stroke of the base isolation system.

The isolator has the capacity of providing the restoring force (given by the spring) and the capacity of limiting the maximum displacements (given by the friction force originated at the slider). Consequently, a force is transmitted to the structure equal to the combination of the friction force, due to the friction of the slider, and the reaction force of the spring as a function of the stiffness of the spring. 
Table 1 Damage limit states and thresholds considered for the design of the video wall room.

\begin{tabular}{clc}
\hline Type of damage (DS) & Classification & EDP \\
\hline DS1: Lateral deformation of a video component & Non-structural & $\Delta$ \\
\hline DS2: Hammer effect on the corner & Non-structural & $\delta$ \\
\hline $\begin{array}{c}\text { DS3: acceleration-dependent damages on me- } \\
\text { chanical components }\end{array}$ & Non-structural & a \\
\hline $\begin{array}{c}\text { DS4: achievement of the maximum allowable } \\
\text { stroke of the base isolation system }\end{array}$ & Structural & $\Delta L$ \\
\hline
\end{tabular}

In Table $1, \Delta$ and a represent the absolute displacement and acceleration of the video's supporting structure, $\delta$ is relative displacement of two orthogonal faces of the supporting structures, $\Delta L$ refers to the base isolation system's stroke.

\section{EVALUATION OF DAMAGE PROBABILITY}

The calculation of $P_{f}\left(\frac{Z}{H}, D S\right)$ defined in Eq. 1 can be summarized according to the following steps:

1. Select the damage state DS and evaluate the corresponding fragility curve $P(D S \mid E D P)$ by means of a lognormal distribution. The selected values of $\mu$ and $\sigma$ are reported in Table 2 .

2. Evaluate the PDF of mean wind speed annual maxima $f(I M \mid Z / H)$ at the reference height $Z / H$ according to [18] for suburban terrain, which is compatible with the mean wind profile of the wind tunnel tests.

3. Evaluate the maximum structural response component EDP for each realization of the experimentally recorded acceleration, i.e., 15 values.

4. Assess the PDF of EDP by means of a GEV distribution that gives the best fitting of the experimental values.

5. Repeat steps 4-5 for all possible IM values to find $P_{f}$ by sampling.

Table 2 Fragility curves: mean values and standard deviations [14].

\begin{tabular}{ccccc}
\hline Parameters & $\Delta$ & $\delta$ & $\mathrm{a}$ & $\Delta \mathrm{L}$ \\
\hline$\mu$ & $0.01 \mathrm{~m}$ & $0.002 \mathrm{~m}$ & $0.5 \mathrm{~g}$ & $0.1 \mathrm{~m}$ \\
$\sigma$ & 0.5 & 0.5 & 0.6 & 0.5 \\
\hline
\end{tabular}

\section{NUMERICAL RESULTS}

Figure 6 shows the annual damage probabilities $P_{f}$ of DS1, DS2, DS3 and DS4, as a function of the height above ground $z / \mathrm{H}$ for video wall room integrated in a high-rise building by accounting for the occurrence of damages associated to the video components with and without a base isolation system. Reductions of more than $50 \%$ are noticeable at the top floor for DS1, DS2 and DS3. It is worth noticing that higher values associated to $\mathrm{z} / \mathrm{H}=0.83$ are due to relevant peak accelerations recorded during the wind tunnel tests. For this reason, the damage probability associated to DS4, which represent the exceeding of the maximum stroke of the base isolations system, is significant only for $z / \mathrm{H}=0.83$. 
a)

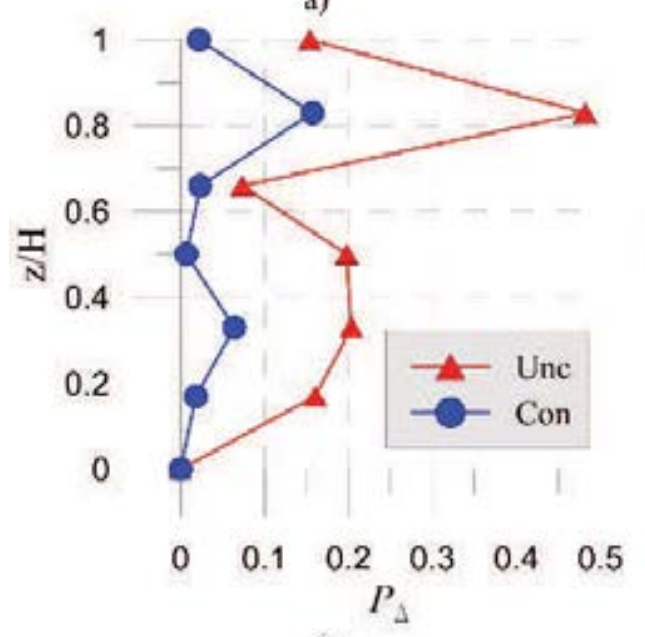

c)

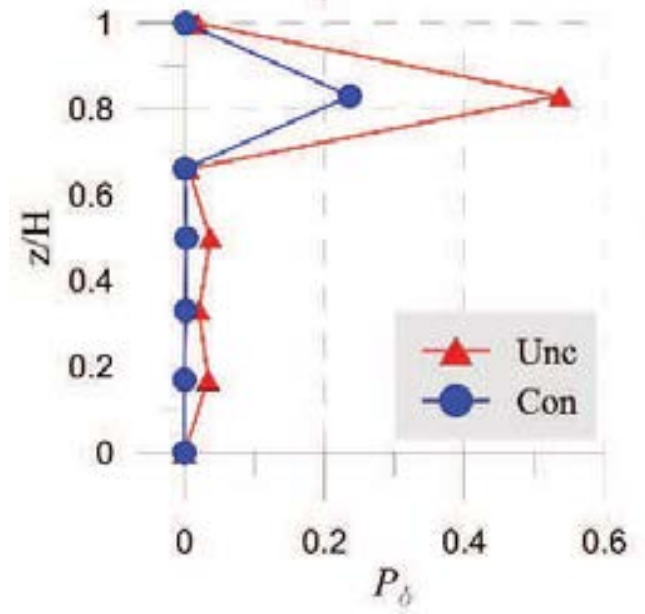

b)

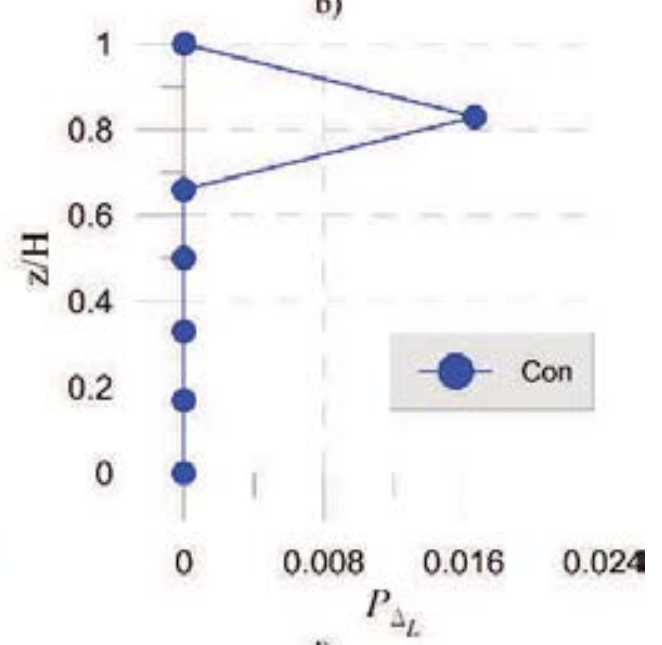

d)

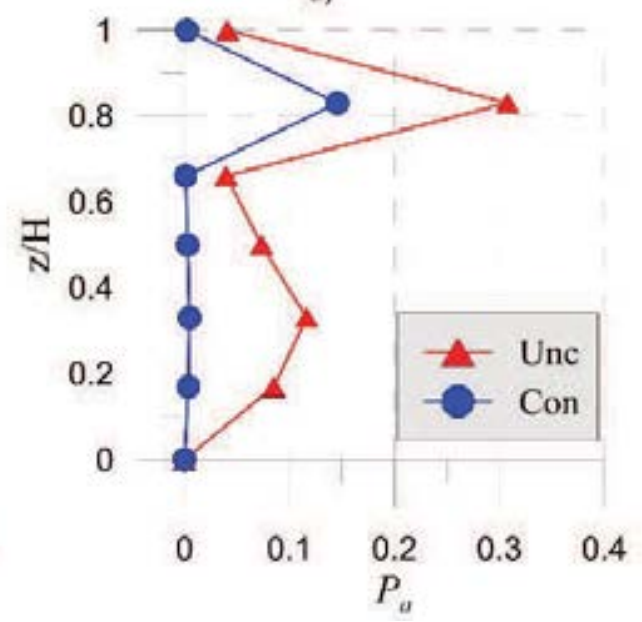

Fig. 6 Annual damage probability as a function of the floor height $\mathrm{z} / \mathrm{H}$ varying between 0 and 1 with (Con) and without (Unc) the base isolation system: a) DS1); b) DS4; c) DS2; d) DS3.

\section{CONCLUSIONS}

The paper investigates the behavior of a base isolation system calibrated to increase the reliability of non-structural elements affected by wind induced acceleration at building's floors. A probabilistic framework for fragility assessment has been developed whose main features are:

- numerical simulations are carried out on a FE model of the video room by using the floors' accelerations measured during aeroelastic wind tunnel tests on a scaled model of the high-rise building ;

- uncertainties associated with the experimental assessment of the wind-induced accelerations and with the structural modeling and the damage estimation are considered;

- the parameters of the base isolation system with hysteretic non-linear behavior are calibrated as a function of location along the building height to avoid the excessive lateral deformation of the video components, the hammer effect at the corner, the acceleration-related damage and the exceedance of displacement limits of the isolation devices;

- the isolation system performance was discussed through a fragility analysis to compute the probability of exceeding predetermined displacements and acceleration 
thresholds with and without the control system. It was observed that on the building top the reliability was increased of more than $50 \%$.

\section{ACKNOWLEDGEMENTS}

A special thanks to the H-Sign srl company to sponsoring this research, to Prof. Giuseppe Piccardo and Dr. Andrea Freda for their advice and assistance during the experimental tests in the DICCA Wind Tunnel of the University of Genoa. Mr. Davide Perazzetti is grateful for his support during the model construction. Prof. Giuseppe Maddaloni, Prof. Antonio Occhiuzzi and Prof. Andrea Prota are gratefully acknowledged for their support during the experimental model dynamic identification through shaking table experiments at the University of Napoli Federico II, Italy.

\section{REFERENCES}

[1] The International Organisation for Standardization. ISO 6897:1984. Guidelines for the evaluation of the response of occupants of fixed structures, especially buildings and off-shore structures, to low-frequency horizontal motion $(0,063$ to $1 \mathrm{~Hz})(1982)$.

[2] The International Organisation for Standardization. ISO 10137. Bases for design of structures - Serviceability of buildings and walkways against vibrations. Ethiopian standard agency (2012).

[3] AIJ-GEH-2004. Guidelines for the evaluation of habitability to building vibration. Architectural institute of Japan (2004).

[4] National Research Council of Canada. National Building Code of Canada. Canadian commission on building and re codes (2016).

[5] Hansen R., Reed J., Vanmarcke E., Human response to wind-induced motion of buildings. Journal of Structural Engineering (1973) 99, 66-74.

[6] Guidelines for the evaluation of the response of occupants of fixed structures, especially buildings and offshore structures, to low frequency horizontal motion (0.063 to $1.0 \mathrm{~Hz})$ ISO $6897: 1984$

[7] Bases for design of structures - Serviceability of buildings and walkways again vibrations (ISO 10137:2007). Smith, Bryan Stafford, Coull Alex, 1991.Tall Building Structures: Analysis and Design, Willey, July (1991).

[8] Iemura H., Taghikhany T., Jain S.K., 2007. Optimum design of resilient sliding isolation system for seismic protection of equipment, Bull. Earthq. Eng. 5 (1) 85-103.

[9] Cornell, C. and Krawinkler, H., 2000. Progress and challenges in seismic performance assessment. PEER Center News, 3(2), 1-3.

[10] Kunnath, S. 2006. Application of the PEER PBEE methodology to the I-880 viaduct. Rep. No. 2006/10. Davis, CA: Univ. of California.

[11] Venanzi I., Ierimonti L., Caracoglia L., 2020. Life-cycle-cost optimization for the wind load design of tall buildings equipped with TMDs. Wind and Structures, An International Journal, 30(4), pp. 379-392

[12] Ierimonti L., Venanzi I., Caracoglia L., 2018. Life-cycle damage-based cost analysis of tall buildings equipped with tuned mass dampers. Journal of Wind Engineering and Industrial Aerodynamics, ISSN: 01676105, 176, 54-64.

[13] Ierimonti L., Caracoglia L., Venanzi I., Materazzi A. L., 2017. Investigation on life-cycle damage cost of wind-excited tall buildings considering directionality effects. Journal of Wind Engineering and Industrial Aerodynamics, ISSN: 01676105, 171, 207-218.

[14] Venanzi I., Lavan O., Ierimonti L., Fabrizi S., 2018. Multi-hazard loss analysis of tall buildings under wind and seismic loads. Structure and Infrastructure Engineering, ISSN: 15732479, 4(10), pp. 1295-1311. 
[15] Rizzo F, Ricciardelli F, Maddaloni G, Bonati A, Occhiuzzi A, 2020. Experimental error analysis of dynamic properties for a reduced-scale high-rise building model and implications on full-scale behavior. Journal of Building Engineering, 28.

[16] CEN (Comité Européen de Normalization), Eurocode 1: Actions on structures - Part 1-4: General actions - Wind actions, EN-1991-1-4, 2005.

[17] Aslani H., Miranda E., 2005. Probabilistic earthquake loss estimation and loss disaggregation in buildings, Report no. 157, in: The John A. Blume Earthquake Engineering Center, 2005.

[18] ASCE/SEI 7-16, 2017. Minimum Design Loads and Associated Criteria for Buildings and Other 583 Structures. American Society of Civil Engineers. 